\title{
Evaluation of job satisfaction of practice staff and general practitioners: an exploratory study
}

Katja Goetz ${ }^{1 *}$, Stephen M Campbell ${ }^{1,2}$, Jost Steinhaeuser ${ }^{1}$, Bjoern Broge ${ }^{3}$, Sara Willms ${ }^{3}$ and Joachim Szecsenyi ${ }^{1,3}$

\begin{abstract}
Background: Primary care teams' job satisfaction is an important issue in quality of care. The purpose of our study was to evaluate the job satisfaction of general practitioners (GPs) and non-physician staff and to explore the elements that may impact on overall job satisfaction for GPs and non-physician staff separately.

Methods: The study was based on data from the European Practice Assessment and used an observational design. Job satisfaction was measured with the 10-items Warr-Cook-Wall questionnaire with 7-point-Likert scales. Job satisfaction of GPs and non-physician staff was compared and impact on overall job satisfaction was analysed with stepwise linear regression analyses for both samples separately.

Results: The study population consisted of 2878 non-physician staff (mean age: 38 years) and 676 GPs (mean age: 50 years). The actual mean working time per week of GPs was 50.0 hours and of practice staff 26.0 hours. Both were satisfied with colleagues and fellow workers (mean $=5.99$ and mean $=6.18$ respectively) and mostly dissatisfied with their income (mean $=4.40$ and mean $=4.79$ respectively). For GPs the opportunity to use their abilities $(\beta=0.638$ ) and for non-physician staff recognition for their work $\beta=0.691$ ) showed the highest scores of explained variance $\left(R^{2}=0.406\right.$ and $R^{2}=0.477$ respectively) regarding overall job satisfaction.

Conclusions: Non-physician staff evaluate their job satisfaction higher than GPs except recognition for work. Job satisfaction of members of primary care teams is important because poor satisfaction is associated with suboptimal healthcare delivery, poor clinical outcomes and higher turnover of staff.
\end{abstract}

\section{Background}

Primary care teams' job satisfaction is an important issue in quality of care for a number of reasons. Poor satisfaction is associated with suboptimal healthcare delivery and poor clinical outcomes, for instance due to adverse events and reduced patient adherence [1,2]. Job dissatisfaction is a major cause of nurses' turnover and a shortage of nonphysician personnel $[3,4]$. Another negative consequence of high turnover is a loss of continuity of care [5]. For the healthcare workers themselves, lowered job satisfaction is also associated with higher levels of stress and burnout $[6,7]$. Furthermore, it may affect patient satisfaction with care [8]. It is known that working conditions have an important impact on job satisfaction and a high workload is associated with a lower performance at primary care practices [9]. Evidence suggests that many health care

\footnotetext{
* Correspondence: katja.goetz@med.uni-heidelberg.de

'Department of General Practice and Health Services Research, University of Heidelberg, Germany

Full list of author information is available at the end of the article
}

workers are very dissatisfied with their income and overall working conditions [4].

Feelings of job dissatisfaction and job stress are problems shared by nurses as well as general practitioners (GPs) in western countries $[10,11]$. The Commonwealth Fund surveyed GPs from 7 countries to compare different aspects of work and showed that German GPs have the highest workload and were most dissatisfied compared to their colleagues from other countries [11]. Germany is based on a Social Security Health system and is funded by means of earmarked premiums. Over 60.000 GPs were registered in 2009 in Germany according to the National Association of Statutory Health Insurance Physicians. In Germany $94 \%$ of all GPs are self-employed. The majority (64\%) works in consist of solo practices [12]. Data about practice location are not consistent. In studies performed in Germany participants rate themselves as either rural or urban located. More objective measurements are not implemented yet [13]. Furthermore, GPs in Germany do
Ciomed Central

(c) 2011 Goetz et al; licensee BioMed Central Ltd. This is an Open Access article distributed under the terms of the Creative Commons Attribution License (http://creativecommons.org/licenses/by/2.0), which permits unrestricted use, distribution, and reproduction in any medium, provided the original work is properly cited. 
not function as a strict gatekeeper as patients have free access to ambulatory specialist services too.

Job satisfaction of GPs decreases with a higher number of hours worked and low income. It increases when there is more contact with other colleagues and greater job variety [14]. One study in Australian compared job satisfaction of physician and non-physician staff and showed that there is overall satisfaction with colleagues but dissatisfaction with income in both groups of employees [15].

The concept of job satisfaction was defined by Herzberg and Mausner [16]. They distinguished between intrinsic satisfaction such as recognition, the work tasks themselves and the level of or responsibility on the one hand, and extrinsic factors like working conditions, company policy or salary, which influence job satisfaction on the other hand [16].

The aim of this study was to evaluate the job satisfaction of German GPs and their non-physician staff separately. The research questions of the study were: 1) How do GPs and non-physician staff evaluate their job satisfaction? 2) Which elements are associated with overall job satisfaction for the group of GPs and the one of non-physician staff?

\section{Methods}

The assessment of job satisfaction among healthcare workers in general practice is one component of the European Practice Assessment (EPA) [17]. EPA consists of a set of validated quality indicators for external and internal assessment, a patient survey of satisfaction with care, a staff job satisfaction survey, an outreach visit by a trained visitor, structured feedback and a team-meeting in the practice [17].

\section{Design and participants}

This observational study was based on a job satisfaction survey. This study used data from the routine implementation of quality management in ambulatory care in Germany, in line with regulations outlined by law in the social code book $\mathrm{V}$ and the directives on quality management of the Federal Joint Committee [18]. There are different quality management systems available for ambulatory care are in Germany such as QEP, ISO 9001:2008, KTQ, EFQM, KPQ and EPA [19]. Practices can choose on their own among these different systems. Data were collected from 676 practices, which had used the European Practice Assessment methodology [17]. The subjects involved in the study included 2947 non-physician staff members (consisting of 2332 physician assistants, 101 nurses, 69 practice managers, 39 secretarial assistants, 337 other workers and 69 with unknown profession) and 676 practice principal physicians of general practices in Germany who have undertaken the EPA.

\section{Measures}

All participants completed the same written questionnaire, which was returned in a pre-paid envelope to the AQUA-institute domiciled in Goettingen, Germany. Data collection took place between May 2004 and September 2007. The questionnaire included the following items:

1) Individuals were asked to complete questions about gender and age, as well as how many hours a week they worked at their practice, and, 2) Job satisfaction was measured with the German validated version of the Warr-Cook-Wall (WCW) job satisfaction scale developed by Warr et al. [20]. The WCW instrument measures overall job satisfaction and satisfaction with nine aspects of work (amount of variety in job, opportunity to use abilities, freedom of working method, amount of responsibility, physical working condition, hours of work, income, recognition for work, and colleagues and fellow workers), with each item rated on a 7 -point Likert scale $(1=$ extreme dissatisfaction to $7=$ extreme satisfaction). A higher overall mean score indicates higher job satisfaction.

\section{Data analysis}

The analyses were performed using SPSS version 18.0 (SPSS Inc., Chicago IL, USA). Differences between physician and non-physician staff were analysed using Student's $\mathrm{t}$ test for continuous variables as appropriate and Chi-square test for categorical variables. The intraclass correlation coefficient (ICC) was calculated to determine consistency between physician and non-physician staff regarding the evaluation of job satisfaction. Furthermore, a descriptive analysis was performed concerning the overall job satisfaction and nine other items of the job satisfaction scale separated for physicians and non-physician staff. Statistical significance of group comparisons for the whole study population and for full-time staff was calculated with Students' unpaired t-test with list wise exclusion of missing data. Means and standard deviations of these items are reported in the results section. Afterwards stepwise linear regression analyses were performed for physicians as well as for non-physician staff separately. Overall job satisfaction was the outcome variable while other elements of satisfaction with work and some characteristics of participants (age, sex, mean weekly working time, location and mode of practice) were potential predictors. An alpha level of $\mathrm{p}<0.05$ was used for tests of statistical significance. However, as this was an exploratory analysis, $p$ values can only be descriptive in nature.

\section{Ethics}

Ethical approval was not necessary. Our study used data from the routine implementation of quality management in ambulatory care in Germany, according to the social 
code book $\mathrm{V}$ and the directives on quality management of the Federal Joint Committee. The questionnaires were completed anonymously. No additional information or data from patients or staff were requested to perform this study.

\section{Results}

\section{Description of the study sample}

The response rate of the job satisfaction survey was $100 \%$, because it is based on a quality management programme and therefore mandatory for the participants. There were 676 practice principals who completed the EPA between May 2004 and September 2007. Out of 3273 staff member questionnaires handed out, 2947 were returned, giving a response rate of $90 \%$. However, 69 individuals with unknown profession were excluded from the sample of non-physician staff. Therefore, in all we involved 2878 non-physician staff members out of 676 primary care practices in this study.

Table 1 presents the individual characteristics of participants. Physicians and non-physician staff showed significant differences in all three individual characteristics. More than $70 \%$ of the physicians were male. The mean age was 50.0 years $(\mathrm{SD}=7.6)$ and mean weekly work time was 50.6 hours $(\mathrm{SD}=12.8)$. The majority of the nonphysician sample was female $(97.2 \%)$. The mean age of that group was 38.3 years $(\mathrm{SD}=12.2)$. The mean weekly work time was 26.0 hours $(\mathrm{SD}=12.5)$. The sample consisted of $46.9 \%$ solo practices and over $51.8 \%$ practices of our sample were located in rural areas in Germany.

The design effect calculated by ICC for physician and non-physician staff regarding the elements of job satisfaction was negligible. For example physical working condition showed an ICC of $0.007(\mathrm{p}=0.431)$, freedom of working method an ICC of $0.013(\mathrm{p}=0.367)$ and amount of responsibility an ICC of $-0.005(\mathrm{p}=0.556)$.

\section{Evaluation of job satisfaction separated for physicians and non-physician staff}

Questions about job satisfaction were completed by 643 GPs (95.1\%) out of the 676 respondents and from 2634 non-physician staff members (91.5\%) out of the 2878 respondents. GPs and non-physician staff were satisfied with 'colleagues and fellow workers' ( mean $=5.99$ and mean $=6.18$ respectively) and mostly dissatisfied with their 'income' $($ mean $=4.40$ and mean $=4.79$ respectively). Non-physician staff had higher levels of satisfaction in questions about job satisfaction with the exception of 'recognition for work'. Details are given in Table 2.

Table 3 shows the evaluation of job satisfaction for the full-time staff. Out of 676 GPs in our study population 523 GPs $(77.4 \%)$ worked 38 hours and more per week. The corresponding number for non-physician staff 743 $(25.8 \%)$. Compared to the whole sample described in Table 2, full-time GPs and non-physician staff were equally satisfied with 'colleagues and fellow workers' ( mean $=5.99$ and mean $=6.13$ respectively) and mostly dissatisfied with their 'income' (mean $=4.37$ and mean $=4.49$ respectively). Moreover, GPs were also dissatisfied with their 'hours of work' (mean $=4.21)$. The results are also depicted in Table 3.

\section{Elements associated with overall job satisfaction separated for physicians and non-physician staff}

The two regression models - for physicians and for nonphysician staff - which are presented in Table 4 and Table 5 report only coefficients with statistically significances at the $\mathrm{p}<0.05$ level.

\section{Non-physician staff}

Table 4 shows the stepwise regression analysis of individual characteristics and the elements of satisfaction with aspects of work on overall satisfaction for non-physician staff. A model with 11 steps was carried out and explained more than $70 \%\left(R^{2} \sim 0.70\right)$ of the variance of the dependent variable 'overall job satisfaction'. These were all nine elements of satisfaction with aspects of work, 'mean weekly working time' and 'age'. In the first step of the stepwise regression analysis the item 'recognition for work' showed the highest score $\left(R^{2}=0.477\right)$ of explained variance. The variables sex, location and mode of practice were not included in the regression model since $\mathrm{p}>0.05$.

\section{Physicians}

Table 5 shows the stepwise regression analysis of individual characteristics and elements of satisfaction with

Table 1 Characteristics of the participants

\begin{tabular}{lll}
\hline & $\begin{array}{l}\text { Physician } \\
(\mathbf{n}=\mathbf{6 7 6})\end{array}$ & Non-physician staff (n= 2878) \\
\hline Age & $50.13(7.59)$ & $38.31(12.24)$ \\
{$[$ mean (SD)] } & & \\
Sex (male) & $70.80 \%$ & $2.80 \%$ \\
Mean weekly working time $[$ mean (SD)] & $50.63 \mathrm{~h}(12.85)$ & $26.03 \mathrm{~h}(12.25)$ \\
\hline
\end{tabular}

SD standard deviation

\#Statistical significance $p<0.05$ 
Table 2 Job satisfaction of all practice staff for each of the 10 items on the Warr-Cook-Wall (WCW) job satisfaction scale*

\begin{tabular}{llll}
\hline WCW items & $\begin{array}{l}\text { Physician } \\
\text { (n= 643) } \\
\text { Mean } \\
\text { (SD) }\end{array}$ & $\begin{array}{l}\text { Non-physician } \\
\text { staff } \\
\text { (n = 2634) } \\
\text { Mean (SD) }\end{array}$ & p-Value \\
& $\begin{array}{llll}\text { M } \\
\end{array}$ & & \\
\hline 1. Amount of variety in job & $5.70(1.23)$ & $5.94(1.15)$ & $<0.001$ \\
2. Opportunity to use abilities & $5.37(1.53)$ & $5.82(1.17)$ & $<0.001$ \\
3. Freedom of working & $5.66(1.41)$ & $5.82(1.23)$ & 0.005 \\
method & & & $<0.001$ \\
4. Amount of responsibility & $5.64(1.36)$ & $5.92(1.34)$ & $<0.001$ \\
5. Physical working condition & $5.19(1.45)$ & $5.63(1.25)$ & $<0.001$ \\
6. Hours of work & $4.43(1.67)$ & $5.75(1.32)$ & 0.001 \\
7. Income & $4.40(1.60)$ & $4.79(1.65)$ & $<0.001$ \\
8. Recognition for work & $5.57(1.62)$ & $5.41(1.49)$ & $<0.001$ \\
9. Colleagues and fellow & $5.99(1.00)$ & $6.18(1.02)$ & \\
workers & & & \\
10. Overall job satisfaction & $5.56(1.12)$ & $5.95(1.05)$ &
\end{tabular}

*Possible score for each item between 1 (extremely dissatisfied) and 7 (extremely satisfied).

"Statistical significance $\mathrm{p}<0.05$.

SD standard deviation.

aspects of work on overall satisfaction for GPs. A model with nine steps was carried out and explained more than $71 \%\left(R^{2} \sim 0.71\right)$ of the variance of the dependent variable 'overall job satisfaction'. These were all nine variables of elements of satisfaction with aspects of work. In the first step of the stepwise regression analysis the item 'opportunity to use abilities' showed the highest score $\left(R^{2}=0.406\right)$ of explained variance. The variables sex, gender, mean weekly working time, location and

Table 3 Job satisfaction of full-time practice staff for each of the 10 items on the Warr-Cook-Wall (WCW) job satisfaction scale*

\begin{tabular}{|c|c|c|c|}
\hline WCW items & $\begin{array}{l}\text { Physician } \\
(n=523) \\
\text { Mean } \\
\text { (SD) }\end{array}$ & $\begin{array}{l}\text { Non-physician } \\
\text { staff } \\
(n=743) \\
\text { Mean (SD) }\end{array}$ & p-Value ${ }^{\#}$ \\
\hline 1. Amount of variety in job & $5.66(1.24)$ & $5.78(1.24)$ & 0.086 \\
\hline 2. Opportunity to use abilities & $5.31(1.55)$ & $5.76(1.19)$ & $<0.001$ \\
\hline $\begin{array}{l}\text { 3. Freedom of working } \\
\text { method }\end{array}$ & $5.60(1.43)$ & $5.67(1.32)$ & 0.331 \\
\hline 4. Amount of responsibility & $5.59(1.38)$ & $5.83(1.24)$ & 0.001 \\
\hline 5. Physical working condition & $5.09(1.46)$ & $5.40(1.28)$ & $<0.001$ \\
\hline 6. Hours of work & $4.21(1.63)$ & $5.44(1.39)$ & $<0.001$ \\
\hline 7. Income & $4.37(1.58)$ & $4.49(1.70)$ & 0.172 \\
\hline 8. Recognition for work & $5.52(1.30)$ & $5.35(1.47)$ & 0.035 \\
\hline $\begin{array}{l}\text { 9. Colleagues and fellow } \\
\text { workers }\end{array}$ & $5.99(1.00)$ & $6.13(1.08)$ & 0.021 \\
\hline 10. Overall job satisfaction & $5.52(1.11)$ & $5.80(1.12)$ & $<0.001$ \\
\hline
\end{tabular}

*Possible score for each item between 1 (extremely dissatisfied) and 7 (extremely satisfied).

"Statistical significance $p<0.05$.

SD standard deviation. mode of practice were not included in the regression model since $\mathrm{p}>0.05$.

\section{Discussion}

The purpose of our study was to evaluate the elements that have the main impact on overall job satisfaction separated for GPs and non-physician staff. Therefore, the job satisfaction of GPs and their non-physician staff at the same practices was observed. Our results showed that nearly all aspects of job satisfaction were rated higher by non-physician staff than by GPs. Only the item 'recognition for work' scored better for GPs than for non-physician staff. This difference remained for most questions of job satisfaction when only those who were full time were included in the analysis with expectation for amount of variety in job, freedom of working method and income. All participants, GPs and non-physician staff alike, were mostly dissatisfied with their income; GPs were more dissatisfied with their hours of work than non-physician staff; which might reflect the fact that the working hours of GPs in Germany are higher than in any other country in Europe [11,21].

It is not surprising that the item 'recognition for work' had the strongest association with more than $47 \%$ of explained variance of non-physician staff's overall job satisfaction. However, this is higher than in previous research [22]. This study also showed that being appreciated for high performance was most important to job satisfaction of non-physician staff [22]. This is important because recognition of performance facilitates team work. Work satisfaction of primary care teams correlates positively with higher scores for outcome quality measures [23].

The strongest association with overall satisfaction for GPs was the opportunity to use their abilities with more than $40 \%$ of explained variance. While the performance of GPs depends on their own skills and capabilities, it also requires sufficient time and support from non-physician staff [24]. German GPs have the highest rate of patient contacts per week compared to other countries [11]. Enhancing the role of non-physician staff might improve the quality of patient care [25]. However, it has been observed that a higher percentage of staff members per practice could also increase the workload of physicians [26].

\section{Strengths and limitations}

A main strength of our study is that there has been little research on the job satisfaction of both GPs and nonphysician staff in the same primary care practices until now [15]. However, our sample may not be representative for all primary care practices in Germany because we only involved practices which were willing to participate in a quality management system and we had less solo 
Table 4 Associations of individual characteristics and satisfaction of aspects of work of non-physician staff on overall job satisfaction (results of stepwise linear regression analysis, under specification of standardized beta coefficient, $\alpha=5 \%$ )

\begin{tabular}{|c|c|c|c|c|c|c|c|c|c|c|c|}
\hline & Step 1 & Step 2 & Step 3 & Step 4 & Step 5 & Step 6 & Step 7 & Step 8 & Step 9 & Step 10 & Step 11 \\
\hline Recognition for work & 0.691 & 0.540 & 0.449 & 0.398 & 0.331 & 0.291 & 0.266 & 0.244 & 0.235 & 0.239 & 0.239 \\
\hline Amount of variety on job & & 0.356 & 0.297 & 0.241 & 0.229 & 0.171 & 0.165 & 0.162 & 0.158 & 0.158 & 0.164 \\
\hline Colleagues and fellow workers & & & 0.252 & 0.236 & 0.211 & 0.196 & 0.190 & 0.192 & 0.187 & 0.187 & 0.185 \\
\hline Hours of work & & & & 0.202 & 0.164 & 0.147 & 0.139 & 0.122 & 0.119 & 0.116 & 0.117 \\
\hline Physical working condition & & & & & 0.176 & 0.165 & 0.150 & 0.144 & 0.137 & 0.131 & 0.127 \\
\hline Opportunity to use abilities & & & & & & 0.149 & 0.117 & 0.111 & 0.101 & 0.105 & 0.104 \\
\hline Amount of responsibility & & & & & & & 0.101 & 0.100 & 0.091 & 0.092 & 0.091 \\
\hline Income & & & & & & & & 0.071 & 0.072 & 0.067 & 0.068 \\
\hline Freedom of working method & & & & & & & & & 0.051 & 0.049 & 0.054 \\
\hline Mean weekly working time & & & & & & & & & & -0.034 & -0.049 \\
\hline Age & & & & & & & & & & & -0.038 \\
\hline Pseudo $R^{2}$ & 0.477 & 0.581 & 0.628 & 0.659 & 0.677 & 0.688 & 0.693 & 0.696 & 0.697 & 0.698 & 0.699 \\
\hline
\end{tabular}

Only coefficients with statistically significances at the $p<0.05$ level were reported.

practices in our sample than the national average suggests [12]. In 2005, the German government stipulated that health care providers should implement a system of annual assessment of quality management [18]. However, no essential health policy system changes could affect the results during the period of data collection. Furthermore, a systematic bias could be suspected because there are large differences between GPs and non-physician staff regarding the socio-demographic characteristics. However, it is not possible to adjust for these differences in our analysis. Additionally, it was not feasible to pair the data of GPs and non-physician staff on practice level since the number of GPs and non-physician staff varied among the practices. A strong aspect was the availability of large numbers of data on German primary care practices including data from staff. We used internationally validated measures for the evaluation of job satisfaction by physicians and non-physicians. In addition, this was an exploratory study; $\mathrm{p}$ values should be interpreted carefully. Significant results might be due to chance and will need to be confirmed in further targeted studies.

\section{Conclusions}

Non-physician staff members rated their job satisfaction higher than GPs. For GPs and non-physician staff different elements were relevant for the evaluation of their overall job satisfaction. On the one hand, for GPs the opportunity to use their abilities had the strongest association with job satisfaction, whereas for non-physician staff, recognition of their role and performance was most important. However, in both cases, this was offset by the perception of poor income. The findings of this study will be helpful for further activities to improve the working conditions of GPs and non-physician staff from different perspectives. Non-physician staff should be supported in their role implicating recognition and appreciation for performance in practice. Moreover, GPs need support through Continuing Professional Development and a team to enable them

Table 5 Associations of individual characteristics and satisfaction of aspects of work of GPs on overall job satisfaction (results of stepwise linear regression analysis, under specification of standardized beta coefficient, $\alpha=5 \%$ )

\begin{tabular}{|c|c|c|c|c|c|c|c|c|c|}
\hline & Step 1 & Step 2 & Step 3 & Step 4 & Step 5 & Step 6 & Step 7 & Step 8 & Step 9 \\
\hline Opportunity to use abilities & 0.638 & 0.472 & 0.398 & 0.273 & 0.175 & 0.119 & 0.107 & 0.080 & 0.070 \\
\hline Hours of work & & 0.373 & 0.332 & 0.295 & 0.279 & 0.244 & 0.176 & 0.170 & 0.161 \\
\hline Colleagues and fellow workers & & & 0.296 & 0.272 & 0.242 & 0.234 & 0.222 & 0.198 & 0.185 \\
\hline Freedom of working method & & & & 0.272 & 0.235 & 0.232 & 0.215 & 0.212 & 0.201 \\
\hline Amount of variety on job & & & & & 0.220 & 0.229 & 0.230 & 0.215 & 0.204 \\
\hline Income & & & & & & 0.155 & 0.158 & 0.142 & 0.137 \\
\hline Physical working condition & & & & & & & 0.137 & 0.136 & 0.129 \\
\hline Recognition for work & & & & & & & & 0.107 & 0.092 \\
\hline Amount of responsibility & & & & & & & & & 0.085 \\
\hline Pseudo $\mathrm{R}^{2}$ & 0.406 & 0.517 & 0.595 & 0.645 & 0.672 & 0.689 & 0.700 & 0.707 & 0.711 \\
\hline
\end{tabular}

Only coefficients with statistically significances at the $p<0.05$ level were reported.

GP general practitioner. 
to use their abilities. In these premises, further research might focus on whether measures to improve the factors we found, really contribute positively to job satisfaction prospectively.

\section{Acknowledgements}

The authors would like to thank the participating practices and their staff for giving permission to use EPA data for scientific purposes. The authors would also like to give thanks to M. Brodowski, M. Lambarki and P. Wippenbeck from the EPA management team at the AQUA-Institute. This study was funded by the Department of General Practice and Health Services Research.

\section{Author details}

'Department of General Practice and Health Services Research, University of Heidelberg, Germany. ${ }^{2}$ National Primary Care Research and Development Centre, University of Manchester, UK. ${ }^{3}$ AQUA-Institute for Applied Quality Improvement and Research in Health Care, Goettingen, Germany.

\section{Authors' contributions}

KG, SC and JSz initiated and designed the study. SW and BB coordinated the study. KG carried out data analysis and wrote the manuscript. All authors read earlier versions of the manuscript, provided critical comments and approved the final manuscript.

\section{Competing interests}

BB and SW are employed by the AQUA-Institute which disseminates EPA in Germany. JSz is its director and stockholder.

Other authors: No conflict of interest declared.

Received: 2 August 2011 Accepted: 12 December 2011

Published: 12 December 2011

\section{References}

1. Wallace JE, Lemaire JB, Ghali WA: Physician wellness: a missing quality indicator. Lancet 2009, 374:1714-21.

2. Gardulf A, Orton M-L, Eriksson LE, Undén M, Arnetz B, Nilsson Kajermo K, Nordström G: Factors of importance for work satisfaction among nurses in a university hospital in Sweden. Scand J Caring Sci 2008, 22:151-60.

3. Lum L, Kervin J, Clark K, Reid F, Sirola W: Explaining nursing turnover intent: job satisfaction, pay satisfaction, or organizational commitment? Journal of Organizational Behavior 1998, 19:305-20.

4. Lu H, While AE, Barriball L: Job satisfaction among nurses: a literature review. Int J Nurs Stud 2005, 42:211-27.

5. Freeman GK, Olesen F, Hjortdahl P: Continuity of care: an essential element of modern general practice? Fam Pract 2003, 20:623-7.

6. Blegen M: Nurses' job satisfaction: A meta-analysis of related variables. Nurs Res 1993, 42:36-41.

7. Kalliath $T$, Morris R: Job satisfaction among nurses. A predictor of burnout levels. JONA 2002, 32:648-54.

8. Szecsenyi J, Goetz K, Campbell S, Broge B, Reuschenbach B, Wensing M: Is the job satisfaction of primary care team members associated with patient satisfaction? BMJ Qual Saf 2011, 20:508-14.

9. Linzer $M$, Baier Manwell L, Williams ES, et al: Working conditions in primary care: physician reactions and care quality. Ann Intern Med 2009, 151:28-36.

10. Aiken $\mathrm{LH}$, Clarke SP, Sloane DM, et al: Nurses' reports on hospital care in five countries. Health Aff 2001, 20:43-53.

11. Koch K, Miksch A, Schürmann C, Joos S, Sawicki PT: The German Health Care System in international comparison: the primary care physicians' perspective. Dtsch Arztbl Int 2011, 108:255-61.

12. Statistics of ambulatory care in German 2009/2010 [in German]; National Association of Statutory Health Insurance Physicians. [http://www.kbv.de/ 125.html], (accessed 2011 November 4).

13. Steinhaeuser J, Joos S, Szecsenyi J, Miksch A: A comparison of the workload of rural and urban primary care physicians in Germany: analysis of a questionnaire survey. BMC Fam Pract 2011, 12:112.

14. Van Ham I, Verhoeven AAH, Groenier KH, Groothoff JW, De Haan J: Job satisfaction among general practitioners: a systematic literature review. Eur J Gen Pract 2006, 12:174-80.
15. Harris MF, Proudfoot JG, Jayasinghe UW, et al: Job satisfaction of staff and the team environment in Australian general practice. Med J Aust 2007, 186:570-3.

16. Herzberg F, Mausner B, Snyderman BB: The motivation to work. John Wiley \& Sons, Inc: New York; 21967.

17. Engels $Y$, Dautzenberg $M$, Campbell $S$, et al: Testing a European set of indicators for the evaluation of the management of primary care practices. Fam Pract 2006, 23:137-47.

18. Quality management directive on medical and dental care [in German] Berlin (Germany); Federal Joint Committee (G-BA); 2005. [http://www.gba.de/downloads/62-492-3/RL_QM-Vertragsarzt-2005-10-18.pdf], (accessed 2011 November 4)

19. Stiftung Warentest: Qualität verordnet. Journal Gesundheit 2009, 11:86-9.

20. Warr PJ, Cook J, Wall T: Scales for the measurement of some work attitudes and aspects of psychological well-being. Journal of Occupational Psychology 1979, 52:129-48.

21. Kroneman MW, Van der Zee J, Groot W: Income development of general practitioners in eight European countries from 1975 to 2005. BMC Health Serv Res 2009, 9:26.

22. Blegen MA, Goode CJ, Johnson M, Maas ML, McCloskey JC, Moorhead SA: Recognizing staff nurse job performance and achievement. Res Nurs Health 1992, 15:57-66.

23. Mohr DC, Young GJ, Meterko M, Stolzmann KL, White B: Job satisfaction of primary care team members and quality of care. Am J Med Qual 2011, 26:18-25.

24. Schoen C, Osborn R, Huynh PT, Doty M, Peugh J, Zapert K: On the front lines of care: primary care doctors' office systems, experiences, and views in seven countries. Health Aff (Millwood) 2006, 25:w555-71.

25. Phillips CB, Pearce C, Kljakovic M, Sibbald B, Dwan K, Porritt J, Yates R: Enhancing care, improving quality: the six roles of the general practice nurse. MJA 2009, 191:92-7.

26. Wensing M, Van den Hombergh P, Van Doremalen J, Grol R, Szecsenyi J. General practitioners' workload associated to practice size rather than chronic care organisation. Health Policy 2009, 89:124-29.

\section{Pre-publication history}

The pre-publication history for this paper can be accessed here: http://www.biomedcentral.com/1471-2296/12/137/prepub

doi:10.1186/1471-2296-12-137

Cite this article as: Goetz et al.: Evaluation of job satisfaction of practice staff and general practitioners: an exploratory study. BMC Family Practice 2011 12:137.

\section{Submit your next manuscript to BioMed Central and take full advantage of:}

- Convenient online submission

- Thorough peer review

- No space constraints or color figure charges

- Immediate publication on acceptance

- Inclusion in PubMed, CAS, Scopus and Google Scholar

- Research which is freely available for redistribution

Submit your manuscript at www.biomedcentral.com/submit
C Biomed Central 